\title{
ITINERÁRIO DE BANDEIRA: NACIONAL, REGIONAL E MUNICIPAL
}

\author{
ITINERARY OF BANDEIRA: NATIONAL, REGIONAL AND \\ MUNICIPAL
}

\author{
Éverton Barbosa CORREIA ${ }^{13}$
}

\begin{abstract}
RESUMO: A obra de Manuel Bandeira é largamente conhecida como uma das mais características de nossa modernidade, a despeito de seu lirismo inconteste. Por isso, convém esmiuçar sua representatividade, perante índices de nossa modernidade, qualificando-a particularmente. Para tanto, tomaremos o Itinerário de Pasárgada como ponto de apoio para a apreciação de alguns poemas, a saber, "Os sapos", "Evocação do Recife" e "Declaração de amor". Assim, espera-se enlaçar a expressão subjetiva da escritura bandeiriana à representação social daí decorrente, considerando as cidades por onde o poeta passou e a sua experiência literária correspondente. Com isso, a dimensão pública de sua produção se apresenta a partir de seu traço pessoal, através de elementos de composição.
\end{abstract}

PALAVRAS-CHAVE: Poesia brasileira moderna; Manuel Bandeira; Subjetividade; Memória.

ABSTRACT: The work of Manuel Bandeira is widely known as one of the most characteristic ones of Brazilian modernity, despite his unavoidable lyricism. Therefore, it is shall to search its social representativeness, according to features of our modernity, qualifying it particularly. To this end, it is taken the book Itinerário de Pasárgada as support for the assessment of some poems namely "Os sapos”, "Evocação do Recife” and "Declaração de amor". Thus, it is hoped to join the subjective expression of Bandeira's writing with the correspondent social representation, considering the cities where the poet passed by and where he had his literary experience. With this, the public dimension of his production is presented from his personal stroke through compositional elements.

\footnotetext{
${ }^{13}$ Departamento de Educação. Programa de Pós-Graduação em Letras - Faculdade de Letras Universidade Federal de Mato Grosso do Sul (UFMS), campus de Três Lagoas - CEP 79603-011 - Três Lagoas - MS - Brasil - E-mail: evertonbcorreia@gmail.com
} 
KEYWORDS: Brazilian modern poetry; Manuel Bandeira;

Subjectivity; Memory.

\section{Um busto vagando pelo Recife}

Pouco antes de seu falecimento, Manuel Bandeira se viu diante da seguinte situação insólita: ter o seu busto esculpido por Celso Antonio, mas impedido de ser afixado em praça pública no Recife (BARBOSA, 2009, p.LXXXIII). O episódio, pouco conhecido, serve para iluminar a compreensão do poeta através do conjunto de contradições em que esteve envolto, quer consideremos sua relação com a cidade em que nascera, o seu desejo de exibição ou a conversão de sua figura em objeto de culto. Até porque imaginar o busto do poeta vagando pelas ruas do Recife não deixa de ser algo representativo da vida que ele teve, da poesia que quis e do perfil de poeta que talhou para si durante toda a sua produção. Reconhecido nacionalmente como portador de uma das vozes mais características da poesia brasileira moderna, o sujeito Manuel Carneiro de Sousa Bandeira nunca cortou os laços que o atavam à província natal, fosse pelo cordão da parentela que ligava aquele menino bem-nascido - referido no poema "Epígrafe" - às famílias tradicionais pernambucanas, fosse pela constelação de amigos que manteve na capital do estado, fosse pela experiência infantil que forjou sua afetividade e, por extensão, todo o imaginário do nosso poeta de Pasárgada.

Caso menos controverso é o do historiador Mário Melo, que, tendo ficado à frente do Instituto Arqueológico, Histórico e Geográfico Pernambucano (IAHGP), durante muito tempo, não hesitou em limitar a consagração do poeta, sob o aparato da constituição do estado consoante a qual o espaço público não deve ser alvo de personalização, o que supostamente aconteceria quando um logradouro público recebesse o nome de personalidade viva. Cioso que era para com a memória provinciana, instaurou um problema para toda a província, já que não podia abrir uma exceção para o poeta, embora todos soubessem que Manuel Bandeira não iria exatamente se beneficiar do evento e pudesse contar inclusive com importantes signatários da província a seu favor. Para piorar o caso, Manuel Bandeira já não residia em Pernambuco há muito e pelo ofício que exercia, bem como pelas instituições a que estava vinculado, figurava muito mais como um cidadão carioca com interesses nacionais do que como um provinciano arraigado à matéria regional. Tudo isso concorreu para jogar lenha na fogueira da vaidade pernambucana, que animava os seus detratores e também ao poeta, que insistia em se ver esculpido em praça pública. Por mais inusitado que se nos pareça hoje, este foi um dos últimos conflitos pessoais com que viveu o poeta: ver-se, ou não, gravado em pedra na sua cidade natal. 
Se, através de um episódio da vida de Manuel Bandeira, podemos identificar o paradoxo irresolutamente brasileiro entre o público e o privado, tal problema ganha maiores proporções se o estendermos para sua vida anterior ao episódio e, mais ainda, para sua obra. Pois é bem sabido que a poesia bandeiriana é atravessada como poucas pela biografia de seu autor, que se oferece de pronto como objeto de representação. Este traço talvez comum ao fazer poético ganha um sentido a mais quando circunstanciado na obra do poeta pernambucano, devido à maneira singular com que ele trata a matéria social brasileira, passando direta e inapelavelmente pela sua experiência sensível. Desse modo, o delineamento do seu sujeito vem a ser uma maneira sinuosa de apresentar os problemas sociais presentes nas suas composições, assim como parece inconcebível fazer qualquer consideração acerca da representação social daquela poesia sem passar necessariamente pelo esmiuçamento do seu perfil, que conjuga o homem e o poeta Manuel Bandeira.

Sim, porque talvez nenhum outro poeta brasileiro do século XX haverá de ter sido tão fotografado, pintado e esculpido quanto Manuel Bandeira. Ele mesmo já confessou mais de uma vez certo gozo no seu exibicionismo e a consideração ganhará maior relevo se levarmos em conta que, em sua poesia, acontece algo semelhante. Quer dizer, assim como o poeta se esmera em exibir-se para a câmera, para o quadro ou para o cinzel, também o faz quando se exibe como objeto de poesia. Melhor dizendo, o seu sujeito poético se constrói deliberadamente a partir da persona que se exibe falha, espontânea, precária e se deixa absorver completamente pela matéria, pela forma e pelos meios circunstantes. Aí reside, pois, um problema agudo acionado pela poesia bandeiriana, na medida em que as circunstâncias a que poeta esteve submetido compõem não só o seu imaginário, como também o repertório de temas e tratamentos presentes na sua poesia. Isso tanto pode ser verificado quando nos reportamos à sua doença, à sua família, aos seus amigos e aos lugares que frequentou e lhes consignou um valor significativo, seja um beco, uma rua, um morro ou uma cidade. Como a visada que aqui se esboça requer certa perspectiva, incidiremos nosso olhar para as cidades que laureiam a produção do poeta, ao invés das ruas e becos correspondentes.

A questão interessa sobretudo porque a condição de estar situado ocasionalmente numa ou noutra cidade pode servir de índice para um discurso nacionalizante, regionalizante ou municipalizante. Antes de entrarmos na consideração de quando Bandeira começou a ser ou deixou de ser uma coisa ou outra, convém lembrar que ser nacional ou regional é uma questão de cabedal, como pão ou pães o é de opiniães. Ou seja, um ou outro ponto de vista é construído historicamente e não sem interesse. Por isso, o que se intenta aqui é lustrar o perfil de um sujeito que transitou pelos espaços mais variados, ao invés de reforçar tal ou qual ponto de vista previamente esboçado. Para tanto, o caso de Manuel Bandeira se faz especialmente interessante porque ele conseguiu ser amigo de Mário de Andrade sem deixar de o ser de Gilberto Freyre; foi lido na Semana de Arte Moderna de 1922 e fez o único poema a constar no Livro do Nordeste, organizado por Gilberto Freyre em 1925. Foi missivista assíduo de 
Mário de Andrade e colaborador ativo do Jornal A província - dirigido por Gilberto Freyre -, e costumeiro revisor do antropólogo pernambucano. Como ambos os episódios foram retocados pelo poeta no seu Itinerário, talvez valha o cotejo dos respectivos poemas com os comentários correspondentes feitos pelo próprio autor. Por uma questão histórica, convém iniciar pelo poema "Os sapos", lido por Ronald de Carvalho no Teatro Municipal de São Paulo em 1922, para depois comentarmos o "Evocação do Recife" publicado inicialmente no Livro do Nordeste (1925), ao lado de uma crítica de Joaquim Cardozo, intitulada "Manuel Bandeira: um poeta pernambucano" numa época em que Manuel Bandeira não era propriamente uma celebridade. Comecemos, pois, pelo "Os sapos", notadamente naquelas estrofes que, pela ironia, parecem sintetizar o espírito de vanguarda antecipadamente à Semana de 1922, já que foi coligido inicialmente em Carnaval (1919) e decerto escrito antes disso. Conforme consta:

$[\ldots]$

O sapo-tanoeiro,

Parnasiano aguado,

Diz: - 'Meu cancioneiro

É bem martelado.

Vede como primo

Em comer os hiatos!

Que arte! E nunca rimo

Os termos cognatos.

O meu verso é bom

Frumento sem joio,

Faço rimas com

Consoantes de apoio.

Vai por cinqüenta anos

Que lhes dei a norma: 
Reduzi sem danos

A fôrmas a forma.

Clame a saparia

Em críticas céticas:

Não há mais poesia,

Mas há artes poéticas.’

$[\ldots]$

(BANDEIRA, 2009, p.48-49).

O último dístico supracitado encerra um dilema caracteristicamente moderno, qual seja, o de não se submeter a um entendimento geral de poesia, e sim produzir uma arte poética que, de tão individualizada, possa ser identificada pelo timbre da voz do seu autor. Este imperativo, Manuel Bandeira categorizou como poucos contemporâneos seus. Sendo assim, a modernidade de sua expressão se torna inconteste, quer nos fixemos na perspectiva que anima sua produção ou na matéria que a constitui, uma vez que nem uma nem outra desprezam a história ou as referências circunstantes. Ao invés, compõem-se através do passado e sua repercussão no presente, cuja visada só se torna acessível porque ele está situado em tempo e espaço precisos. Curiosamente, observando "Os sapos" as referências contextuais se dão através de elementos da forma, seja pelo reconhecimento do 'Parnasiano aguado', ou ainda, pela rejeição dos 'cognatos' ou reivindicação da 'consoante de apoio'. Acontece que o parnasiano referido não é Olavo Bilac como muitos de seus leitores entenderam, e sim os parnasianos tardios e decadentes, a exemplo de Hermes Fontes e Goulart de Andrade, que eram seus contemporâneos. Aliás, coube ao último ao menos a responsabilidade sobre uma publicação sua, como se vê (BANDEIRA, 2009, p.579):

A propósito desta sátira, devo dizer que a dirigi mais contra certos ridículos do pós-parnasianismo. É verdade que nos versos 'A grande arte é como / Lavor de joalheiro' parodiei o Bilac da "Profissão de fé" ('imito o ourives quando escrevo'). Duas carapuças havia, endereçada uma ao Hermes Fontes, outra ao Goulart de Andrade. O poeta das Apoteoses, no prefácio ao livro, chamara a atenção do público para o fato de não haver nos seus versos rimas de palavras cognatas; Goulart de Andrade publicara uns poemas em que adotara a rima francesa com consoante de apoio (assim chamam os franceses a consoante que 
precede a vogal tônica da rima), mas nunca tendo sido ela usada em língua portuguesa, achou o poeta que devia alertar o leitor daquela inovação e pôs sob o título dos poemas a declaração entre aspas: "obrigado à consoante de apoio". Goulart não se magoou com a minha brincadeira e sete anos depois foi quem arranjou editor para o meu volume de Poesias.

Por isso, o epíteto constante no poema não pode e nem poderia se referir ao Príncipe dos poetas - a quem Manuel Bandeira devotava verdadeira admiração -, mas sim aos seus imitadores decadentes e contemporâneos do poeta pernambucano - de quem pretendia se afastar esteticamente, a despeito da proximidade geracional. Como prova disso, se não bastasse a publicação da Antologia de poetas brasileiros da fase parnasiana feita pelo poeta, de algum modo sua simpatia já tinha sido expressa no seu Itinerário, como se segue (BANDEIRA, 2009, p.585):

O movimento estava já em plena impulsão quando Graça Aranha chegou de Europa, em outubro de 1921, trazendo-nos a sua Estética da vida, que nenhum de nós aceitou. Mas, como escreveu Mário, 'o que ninguém negará é a importância dele para a viabilidade do movimento, e o valor pessoal dele. É lógico: mesmo que o Graça não existisse, nós continuaríamos modernistas e outros viriam atrás de nós, mas ele trouxe mais facilidade e maior rapidez para nossa implantação. Hoje nós somos pra quase toda gente.' Também não quisemos, Ribeiro Couto e eu, ir a São Paulo por ocasião da Semana de Arte Moderna. Nunca atacamos publicamente os mestres parnasianos e simbolistas, nunca repudiamos o soneto nem, de um modo geral, os versos metrificados e rimados. Pouco me deve o movimento; o que eu devo a ele é enorme. Não só por intermédio dele vim a tomar conhecimento da arte de vanguarda na Europa [...], como me vi sempre estimulado pela aura de simpatia que me vinha do grupo paulista.

Se tais considerações apontam para a modernidade presente na poesia de Manuel Bandeira, a partir de considerações contextuais e da vida literária apreensíveis de seu poema citado na Semana de Arte Moderna, outras tantas o serão do "Evocação do Recife", onde a matéria literária se esgarça da memória provinciana que se cruza com a do poeta e confere substância à sua expressão. Para visualizar melhor o problema, detenhamo-nos ao entrecho do poema em que a sua cidade natal é mencionada expressamente (BANDEIRA, 2009, p.107-110): 
"Evocação do Recife"

Recife

Não a Veneza americana

Não a Mauritsstad dos armadores das Índias Orientais

Não o Recife dos Mascates

Nem mesmo o Recife que aprendi a amar depois -

Recife das revoluções libertárias

Mas o Recife sem história nem literatura

Recife sem mais nada

Recife da minha infância [...]

Recife...

Rua da União...

A casa de meu avô...

Nunca pensei que ela acabasse!

Tudo lá parecia impregnado de eternidade

Recife...

Meu avô morto

Recife morto. Recife bom, Recife bem brasileiro como a casa de meu avô.

$[\ldots]$

O Recife sem história nem literatura se torna mais verdadeiro justamente porquanto se apresenta impregnado de autenticidade. Pretender depurar-lhe a história e a literatura funciona no interior do poema, contraditoriamente, para conferir-lhe maior intensidade histórica e literária, porque faz com que a literatura e a história se plasmem numa expressão que é por demais individualizada. Poucos poetas serão tão indivíduos quanto Manuel Bandeira e pouco indivíduo haverá de ser tão sujeito quanto Manuel Bandeira. Sujeito em duplo sentido: porque se deixa absorver pelas circunstâncias e 
porque se impõe imperiosamente nos seus escritos. Senão, vejamos (BANDEIRA, 2009, p.573-574):

$\mathrm{Na}$ 'Evocação do Recife' as duas formas 'Capiberibe Capibaribe' têm dois motivos. O primeiro foi um episódio que se passou comigo na classe de Geografia do Colégio Pedro II. Era nosso professor o próprio diretor do Colégio - José Veríssimo. Ótimo professor, diga-se de passagem, pois sempre nos ensinava em cima do mapa e de vara em punho. Certo dia perguntou à classe: 'Qual é o maior rio de Pernambuco?' Não quis eu que ninguém se me antecipasse na resposta e gritei imediatamente do fundo da sala: 'Capibaribe'. Capibaribe com $a$, como sempre tinha ouvido dizer no Recife. Fiquei perplexo quando Veríssimo comentou, para grande divertimento da turma: 'Bem se vê que o senhor é um pernambucano' (pronunciou 'pernambucano' abrindo bem o $e$ ) e corrigiu: 'Capiberibe'. Meti a viola no saco, mas na 'Evocação' me desforrei do professor, intenção que ficaria para sempre desconhecida se eu não a revelasse aqui.

Claro está que a repetição da palavra produz um efeito melódico incomum, o que foi devidamente justificado pelo poeta como sendo o seu segundo motivo para usar a variação da palavra. Mas, além disso, é oportuno salientar que a variação é também o registro verbal de outra época, que ecoa na boca de seu professor como variante regional, quando, na verdade, é também histórica. Antes de se popularizar como Capibaribe, o rio pernambucano era conhecido como o Capiberibe, ao menos nos círculos ilustrados, o que justifica a correção de José Veríssimo. Se esse jogo de palavras contribui para o entendimento do rio no interior da composição, é ponto pacífico que as referências que remetem à sua doença e à sua família constituem linhas de força da expressão bandeiriana, exatamente porque não podem ser transferíveis a outros sujeitos e caracterizam, por conta disso, a experiência particular do poeta e o seu sujeito, por extensão. Algo semelhante acontecerá se tomarmos por base sua experiência urbana, o que já está sugerido pelos poemas e pelas respectivas análises, na medida em que ilustram sua experiência decorrente de sua vivência no Recife, em São Paulo, no Rio de Janeiro, mas falta ainda o seu modo de transitar do Rio para Petrópolis e o seu trânsito em cidadezinhas do interior do Brasil, a exemplo de Campanha, Quixeramobim e Juiz de Fora.

Por uma questão anedótica, restrinjamo-nos a Juiz de Fora. O episódio é o seguinte: como era amigo de Honório Bicalho devido ao compadrio dos respectivos pais, Manuel Bandeira colaborou ocasionalmente na imprensa juiz-forana, onde teve "polêmica travada nas colunas do Correio de Minas e do Jornal do Commercio, ambos 
de Juiz de fora, entre o poeta e o professor Machado Sobrinho, em torno de um hiato de Mário Mendes Campos, pai de Paulo Mendes Campos” (BARBOSA, 2009, p.LXIV). Como a contenda começou a tomar fôlego, a irmã do poeta que fazia as vezes de sua enfermeira, ao perceber que seu irmão e paciente estava se desgastando com o episódio, lançou-lhe a interpelação de que ele desejava entrar na Literatura Brasileira por Juiz de Fora e fez longa propaganda do intento do irmão. Para quem já tinha a experiência urbana de várias cidades brasileiras, Juiz de Fora não era exatamente uma metrópole àquela época e talvez o desfecho do episódio tenha se devido ao chamamento da irmã do poeta. Independente de qualquer coisa, Juiz de Fora comparece pontualmente na poesia de Manuel Bandeira. Para ilustrar a hipótese, detenhamo-nos a dois exemplos: "Mangue", de Libertinagem, e "Declaração de amor", de Estrela da manhã.

Apesar de pouco comentado, "Mangue" é um poema importante na coletânea que o enfeixa, notadamente pelo seu lugar naquela publicação, vizinho do já mencionado "Evocação do Recife" e de "Belém do Pará", poemas que, pelos seus títulos, oferecem a visão plural do Brasil que animava o poeta, não por uma reivindicação programática, e sim por contingências do ofício, primeiramente de seu pai e depois do próprio poeta. A observação se faz tanto mais curiosa quanto mais considerarmos que há diálogos entre os três poemas de Libertinagem em vários níveis, sejam formais ou de conteúdo. E o comentário ganha relevo quando pensamos que as cidades se entrelaçam na representação e na expressão do autor, que queremos brasileiro. Desse modo, sua expressividade adquire uma tonalidade particular quando ali percebemos a recorrência de temas e formas que atravessam cidades tão distantes geograficamente quanto Belém, Recife e Juiz de Fora. Para encurtar o comentário, detenhamo-nos ao entrecho que cruza Recife e Juiz de Fora através de "Mangue".

\section{$[\ldots]$}

\section{OFERTA}

Mangue mais Veneza americana que o Recife

Mereti Meretriz

Mangue enfim verdadeiramente Cidade Nova

Com transatlânticos atracados nas docas do Canal Grande

Linda como Juiz de Fora!

(BANDEIRA, 2009, p.105). 
A "Oferta" aparece no poema "Mangue" como uma espécie de "coda", que arremata o poema retomando todo o seu discurso estendido nos 51 versos anteriores. Versos livres, irregulares, às vezes rimados e às vezes não, mas que se abrem em direção a tantos outros versos de Manuel Bandeira, que podem ser imediatamente identificados em Libertinagem (1930), mas não só. Vejamos, pois, outro exemplo tirado do livro do poeta imediatamente posterior, Estrela da manhã (1936):

"Declaração de amor"

Juiz de fora! Juiz de fora!

Guardo entre minhas recordações

Mais amoráveis, mais repousantes

Tuas manhãs!

Um fundo de chácara na Rua Direita

Coberto de trapuerabas.

Uma velha jabuticabeira cansada de doçura.

Tuas três horas da tarde...

Tuas noites de cineminha namorisqueiro...

Teu lindo parque senhorial mais segundo reinado do que a

[própria Quinta da Boa Vista

Teus bondes sem pressa dando voltas vadias...

Juiz de fora! Juiz de fora!

Tu tão de dentro deste Brasil

Tão docemente provinciana...

Primeiro sorriso de Minas Gerais!!!

(BANDEIRA, 2009, p.139). 
Comparando este poema com o anterior, podemos ver uma simetria entre os últimos versos de ambos os poemas, quais sejam: "Linda como Juiz de fora!" e "Primeiro sorriso de Minas Gerais!!!”. O paralelismo não se dá exclusivamente pela colocação do verso no corpo do poema, mas também pela pontuação exclamativa e a abertura sugerida a partir daí. Não custa acrescentar que, segundo a fabulação do poeta, o primeiro sorriso de Minas Gerais é justo o de Juiz de fora, lindo. Lindo aqui entra como termo de comparação entre Juiz de fora e a própria beleza. A expressão "Linda como Juiz de fora" pressupõe a cidade mineira como limite de beleza. Beleza - bem entendido - circunstanciada, limitada e pequena como a própria Juiz de fora. Este enunciado sugerido pelo verso se expande quando pensamos nos demais versos de "Mangue" ou na totalidade dos versos de "Declaração de amor", que se encerra com o "Primeiro sorriso de Minas Gerais!!!".

Diante do título de "Declaração de amor", supõe-se de imediato que o poeta vai se dirigir à amada, o que não está descartado se a entendermos como símile de Juiz de fora. No entanto, essa hipótese não descarta a possibilidade de entendermos a declaração de amor a Juiz de fora propriamente. Neste sentido, haveremos de considerar o primeiro verso "Juiz de fora! Juiz de fora!" que se repete anaforicamente no décimo segundo como constituindo uma moldura do quadro que encerra uma imagem singela, sedutora e singular daquela que se quer amada.

Entre os dois versos que clamam e exclamam "Juiz de fora! Juiz de fora!" é que aparecem "um fundo de chácara", "um cineminha namorisqueiro", "um parque senhorial", índices da mesma sociabilidade que apontam simultaneamente para o mundo agrário presente na cidade e os resquícios do Império incrustados no desenho da cidade. Dentro do mesmo quadro, dois versos simétricos aguçam a melancolia de um tempo passado que se arrasta precariamente até o presente do poeta: "Uma velha jabuticabeira cansada de doçura" e "teus bondes sem pressa dando voltas vadias". O bonde é já de si um elemento anacrônico no Brasil moderno e, sem pressa, figura um objeto deslocado de sua função, dando voltas que, pelo seu sem-sentido, parecem vadias. Não custa imaginar aí uma projeção do poeta que se via igualmente deslocado e perdido em seus propósitos: arquiteto e músico falhado. Projeção semelhante a que vislumbramos na jabuticabeira velha e cansada de doçura. Não nos esqueçamos de que o livro Estrela da manhã foi publicado em 1936, portanto, quando o poeta entrara na casa dos cinquenta anos. Se hoje a cifra pode parecer simpática, não o era à época de Manuel Bandeira, quando a expectativa de vida era bem menor, sobretudo para quem convivia com a morte cotidianamente desde a juventude.

Fora da moldura abalizada pelo verso "Juiz de fora! Juiz de fora!" que limita dois momentos do poema, há declarações que trespassam a afetividade do poeta através da cidade, a quem ele já vinha tratando na segunda pessoa por meio do possessivo "Tuas" e que se estende no pronome pessoal "tu”, personalizando a cidade a quem se reporta por ocasião dos enunciados dos seguintes versos: "Tu tão de dentro do Brasil/ 
tão docemente provinciana". O vocativo do verso anterior ao dístico mencionado só reforça a particularidade da cidade, que se escancara no último verso como "Primeiro sorriso de Minas Gerais!!!” Estivesse o dístico descontextualizado, talvez pudesse se referir a uma cidadezinha qualquer, mas tal como está não pode deixar de fazer remissão a Juiz de fora.

A constatação interessa na proporção em que dimensiona o valor da referência para Manuel Bandeira, a quem reputamos incansavelmente o epíteto de poeta moderno, mesmo sem qualificar sua modernidade. Modernidade essa que se faz tanto mais interessante quanto mais a considerarmos caracteristicamente brasileira. Não de um Brasil indeterminado, anacrônico e naturalmente disposto para seus habitantes, mas, ao invés, um Brasil circunstanciado, particularizado e historicizado, como não pode deixar de ser. Também por isso não podemos deixar de assinalar as suas conquistas formais e também conteudísticas, posto que se fundem.

O fato literário a ser destacado do poema de Manuel Bandeira é que sua compreensão de cidade e, por conseguinte, de Brasil, é bastante variada e plástica. Não só devido ao cordão das cidades que aparecem na sua escritura, mas também devido ao entrelaçamento dos poemas que as tematizam, seja quando nos referirmos a versos que lhe são constitutivos a exemplo de "Pará, capital Belém", mas também a outras localidades menos realçadas no mapa do Brasil mas que o compõem igualmente, com força semelhante, apesar da sua pequenez. Pois se até pouco tempo houve quem cantasse a urbanidade como verdadeira boa nova, haveremos de levar em conta que toda a nossa tradição social, histórica e literária passa pelo universo agrário. Não deixa de ser sintomático que movimentos sociais como o dos sem-terra tenham ganhado tanta notoriedade entre nós. Se não é por nossa vocação agrária, decerto apontará para os fracassos de nossa urbanidade.

Manuel Bandeira, por seu turno, observa tudo isso com um olhar perscrutador de quem não se entusiasma com as benesses da modernidade e ao mesmo tempo reconhece que há uma ponte entre o campo e a cidade que exibe o Brasil de que fez parte. Por isso, ele é capaz de ver o beco na rua, a rua na cidade e a cidade no país, que carrega marcas agrárias e carregava muito mais à sua época. Justamente porque não se rende a generalizações e se apresenta como sujeito circunstante, que se oferece quase em sacrifício do que seus olhos viram e ele não pôde transformar, mas tão só registrar através de sua dicção poética, tal como o fez reiteradamente e sempre se espera de seu ofício.

\section{REFERÊNCIAS}


BANDEIRA, M. Carnaval. In: Poesia completa e prosa. Rio de Janeiro: Nova Aguilar, 2009. p.45-72.

Libertinagem. In: Aguilar, 2009. p.95-120. Poesia completa e prosa. Rio de Janeiro: Nova Estrela da manhã. In: Poesia completa e prosa. Rio de Janeiro: Nova Aguilar, 2009. p.121-141. Itinerário de Pasárgada. In: Poesia completa e prosa. Rio de Janeiro: Nova Aguilar, 2009. p.553-616.

BARBOSA, F. de A. Milagre de uma vida. In: BANDEIRA, M. Poesia completa e prosa. Rio de Janeiro: Nova Aguilar, 2009. p.XXXIII-LXXXVI.

Artigo recebido em 30/07/2010 Aceito para publicação em 30/10/2010 